\title{
Upgrade of a Yaw System and its Operation Strategy to a 2 MW Wind Turbine
}

\author{
Jui-Hung Liu ${ }^{I^{*}}$, Jien-Chen Chen ${ }^{2}$ \\ ${ }^{1}$ Southern Taiwan University of Science and Technology, Taiwan \\ ${ }^{2}$ Industrial Technology Research Institute, Taiwan
}

\begin{abstract}
The yawing system in a wind turbine keeps the nacelle facing the incoming wind direction to obtain a better efficiency while it also induces the vibration and fatigue load to the structure. In this paper, the yawing system was discussed and an upgrade plan been provided to a real $2 \mathrm{MW}$ wind turbine. The result has shown the significant improvement on the load output after the update.
\end{abstract}

\section{Introduction}

Yawing system is an important sub-system in a wind turbine. It provides the rotational torque for the turbine head (nacelle + rotor) to rotate into the wind direction to obtain a better energy conversion efficiency. Also, to provide a sufficient brake torque for the nacelle to fixed stably and transfer the dynamic energy to the drive train. Since the wind speed and direction may change continuously every second, the yawing system should turn the nacelle in the same way. However, this is not so realistic for the actuator and may induced extra fatigue load to the structure. Normally, a threshold like $+/-8$ degrees [1-2] misalignment could reduce the yawing action while keeping the efficiency within an acceptable range. Taiwan's wind resource is very good, but it also come with a high turbulent wind condition. From the viewpoint of yaw system, this means the yawing action in such wind farm will be much more than the normal one. Combing the high turbulent wind and high wind speed, the brake torque may not enough to stop the turbine head, the yawing torque not efficiently (need more action and time) or results in an overload trip. The unstable yawing also need another hydraulic brake system to provide larger pressure. This induces other maintenance problems in the hydraulic system to lower the availability of the turbine operation [3-4]. In this paper, a yawing system replacement plan has been implemented to show the performance improvement before and after the update.

\section{System Description: Wind Turbine Model}

In this article, a $2 \mathrm{MW}$ turbine located in central Taiwan was chosen. The basic specification of this turbine is listed in Table 1. The turbine starts to generate the electricity at a wind speed of $3 \mathrm{~m} / \mathrm{s}$, rated at $12 \mathrm{~m} / \mathrm{s}$, then when the average wind speed is over $25 \mathrm{~m} / \mathrm{s}$, the turbine will stop automatically to prevent the dangerous operation under extreme wind condition. Table 1 also shows the yawing strategy of this turbine. When the misalignment between nacelle and the wind direction more than $+/-15$ degrees and the $60 \mathrm{~s}$ wind speed average more than $3.0 \mathrm{~m} / \mathrm{s}$, the main controller system will initiate the yawing action. And the yawing will stop when the misalignment is less than $+/-2$ degrees in $5 \mathrm{~s}$ average.

Table 1. Specs. of the Z72 2 MW turbine.

\begin{tabular}{|c|c|}
\hline \multicolumn{2}{|l|}{ General } \\
\hline Rotor Diameter & $70.65 \mathrm{~m}$ \\
\hline Rotor Speed & Variable, nominal $22.5 \mathrm{rpm}$ \\
\hline Nominal Power & $2.0 \mathrm{MW}$ \\
\hline Rated Wind Speed & $12 \mathrm{~m} / \mathrm{s}$ \\
\hline Cut-in / Cut-out Wind Speed & $3 \sim 25 \mathrm{~m} / \mathrm{s}$ \\
\hline Auto Yawing Start & $\begin{array}{l}+/-15 \text { degrees misalignment } \\
(\text { wind speed } 60 \mathrm{~s} \text { avg. }>=3.0 \\
\mathrm{m} / \mathrm{s} \text { ) }\end{array}$ \\
\hline Auto Yawing Stop & $\begin{array}{l}+/-2 \text { degrees misalignment ( } 5 \\
\text { second average) }\end{array}$ \\
\hline
\end{tabular}

\section{Upgrade Plans}

To upgrade the capability of the yawing mechanism, an appropriate improvement plan is given in this section to select the motor, driver, brake and the necessary components. From the original system documents, a safe range from $1.5 \mathrm{~kW}$ to $3.0 \mathrm{~kW}$ is accepted. A $2.2 \mathrm{~kW}$ capacity is selected from the exisiting products and vendors. This product can satisfy the performance and 
safety requirement at the same time. Table 2 is the specification of the new and original yawing system. The rated current, rated torque, rated power, and the brake torque all have a large increase, which are $30.2 \%, 50.6 \%$, $47 \%$, and $233 \%$ separately.

Table 2. Specs. of the new/original yawing system

\begin{tabular}{ccc}
\hline & Original & New \\
\hline Rated Current & $4.3 \mathrm{~A}$ & $5.6 \mathrm{~A}$ \\
Rated Torque & $15 \mathrm{Nm}$ & $22.6 \mathrm{Nm}$ \\
Rated Power & $1.5 \mathrm{~kW}$ & $2.2 \mathrm{~kW}$ \\
Brake Torque & $15 \mathrm{Nm}$ & $55 \mathrm{Nm}$ \\
\hline
\end{tabular}

To ensure new system can satisfy the operating requirement, simulations have been done by using software DNV-GL Bladed, Adams, and Matlab with new specification parameters like motor electrical parameters and rated values. Combining the high wind speed condition, the system response can be obtained. In Figure 1, a 60 second yawing response is revealed with a $14 \mathrm{~m} / \mathrm{s}$ average wind speed. The yawing command is set to be $0,10,-10$, and 0 degree. The motor torque is the torque after a gearbox which its maximum is $20 \mathrm{Nm}$. This result shows that the new yawing system can be operated within the rated torque under a high wind speed condition. It can meet the system requirement and can be installed to the new turbine.
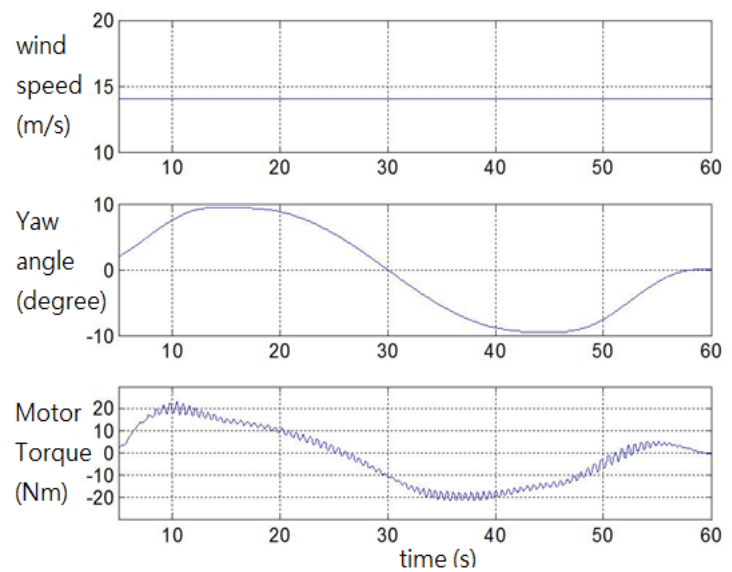

Fig. 1. Simulation Response of the new Yawing System

Besides the motor, other relative necessary components like coupler, control panel, driver, and flange, were also selected to match the requirements. The new motor with integrated into the original mechanism is shown in Figure. 2.

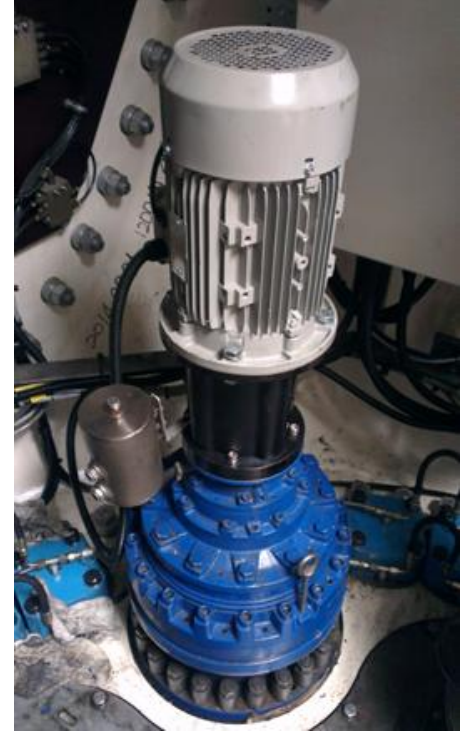

Fig. 2. New Yaw Motor and the original mechanism

Figure 3 is the main control circuit of the new yawing system. $\mathrm{MC} 1$ and $\mathrm{MC} 2$ are in charge of the forward and reverse turning. When over current raised, a message will be sent to the turbine controller. Unlike the simple start/stop (on/off) control of the yaw motor, new system has a speed up and slow down strategy to control the motor speed fixed and stable. This is an important improvement in this upgrade to decrease the vibration to the structure. Other functionalities of the new yawing system are listed below:

1. Speed up/ Slow down strategy: Stable Yawing Speed

2. Brake Capability: Only works when electricity in on. Free mode when black out.

3. Sliping Coupler mode: protect the mechanism in a excessive torque

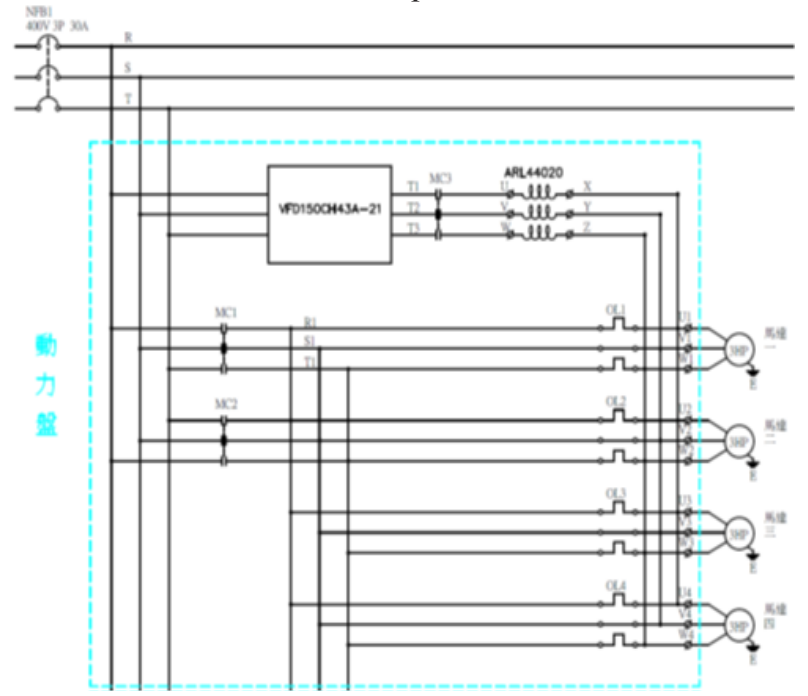

Fig. 3. Main circuit diagram of the new yawing system. 


\section{Verification}

\subsection{Case1: 8 days normal operation analysis}

For a 8 days operation period as shown in Figure 4, under a normal wind speed condition, the yaw motor current is within $10 \mathrm{~A}$. A load increase will occurred in an anti-wind resistance as shown in the middle and bottom of the Figure 4, the current will exceed $20 \mathrm{~A}$. If a forward wind force is faced, motor's speed will too fast to cause the overload. As a whole, in 8 days monitoring, the maximum motor current is about $25 \mathrm{~A}$, this is still below the new system's limit, 32A. So the new system has enough capability to go through the normal wind condition.

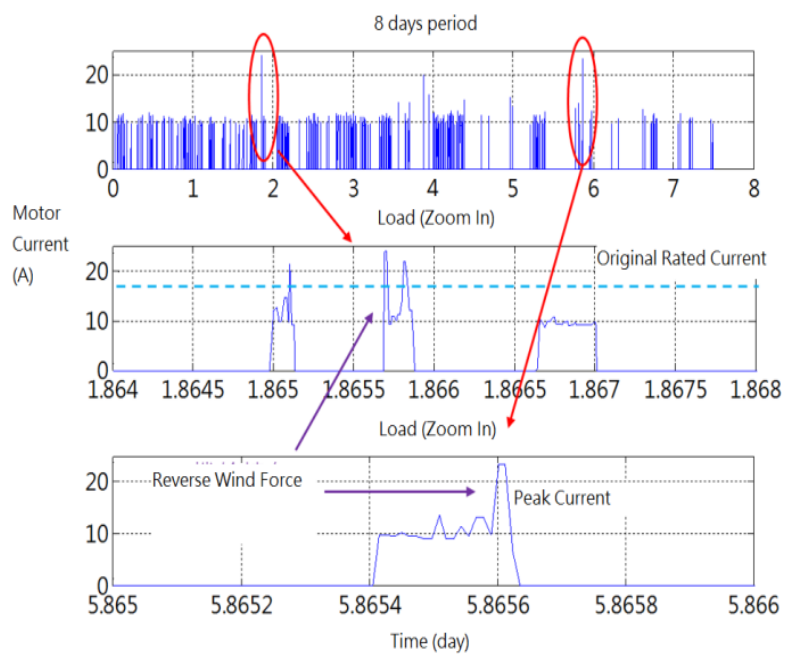

Fig. 4. Long time operation output

\subsection{Case2: Extreme Wind Condition Operation Analysis}

This operation period is only 4.6 hours (15000 seconds) with a wind speed from $20 \mathrm{~m} / \mathrm{s}$ to $35 \mathrm{~m} / \mathrm{s}$ (under Typhoon) but is a very extreme condition with a quite high wind speed and high direction variance. In Figure 5, it can be seen there are many current peaks exceed the rated current $32 \mathrm{~A}$. Because this system also allows $48 \mathrm{~A}$ in 60 seconds and $64 \mathrm{~A}$ in 3 seconds, the yawing system still can survive through this Typhoon wind condition. And when the driver detects an over current, it will reduce the motor frequency to lower the rotational speed to keep the motor operate within the rated value.

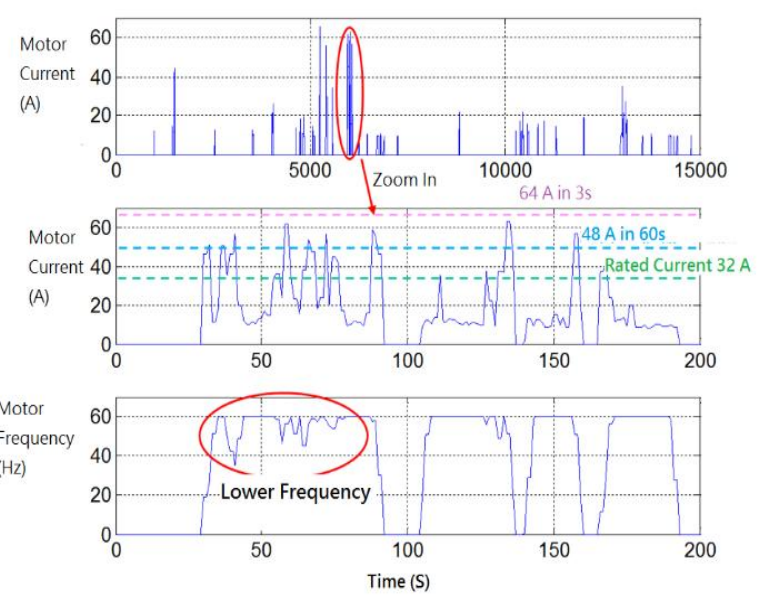

Fig. 5. Yawing System under $20 \sim 35 \mathrm{~m} / \mathrm{s}$ wind condition

\subsection{Case 3: One Year Operation Analysis}

This analysis is a long term observation after the new system has been installed and operated for one year long. We pick up a 13 days data after one year as shown in Figure 6. It can be shown the motor current can be kept in $20 \mathrm{~A}$ (rated current) in most time period. Only two peak values exceed $40 \mathrm{~A}$. This shows the motor still work well after one year. The maximum motor current occurs in Day 7, the zoom-in can be seen in Figure 6(b). At the 3rd second, yawing action started, the motor current increased and the motor frequency also increased to $60 \mathrm{~Hz}$ to keep a constant speed. At the 15 th second, due to a high wind input resistance, yawing system needs an instantaneous power output to remain its original action, so the current increase quickly to $50 \mathrm{~A}$. To protect the system, the driver lowers the frequency to lower the speed of the yaw motor.
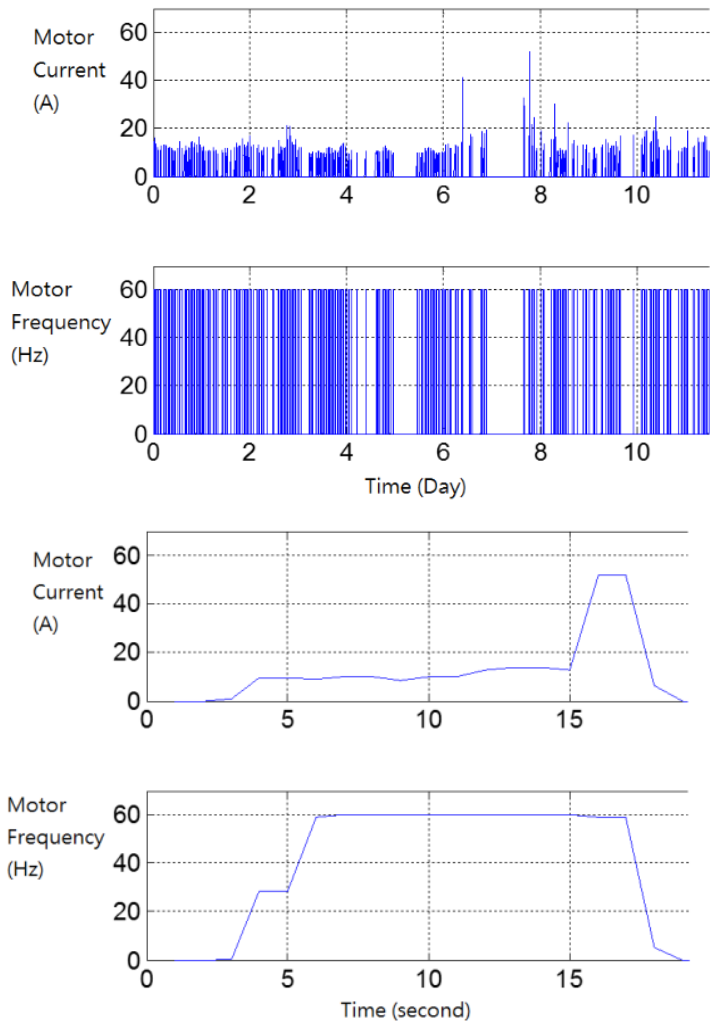
Fig. 6. Operation Data after one year: (a) 13 days data, (b) zoom-in for a specified period

\section{Conclusions}

In this article, we have successfully upgraded a yawing system in a $2 \mathrm{MW}$ wind turbine to increases its moving ability and the peak load resistance. By upgrading yaw motor's rated power, rated current, rated torque, and the brake torque, the final operation data analysis and verification shown that the new system can yawing the nacelle well even under a Typhoon wind condition and a one year long period operation.

Acknowledgments: The financial support provided by Bureau of Energy (Taiwan) is gratefully acknowledged.

\section{References}

1. DNV GL, Guideline for the Certification of Wind Turbines 2010 edition, DNV GL, 2010.

2. IEC, IEC 61400-1 wind turbines - part 1: Design Requirements (third edition), IEC, 2005.

3. C. Moerman, "Harakosan Technical Documentation, User's Guide (HE-0378-R03)", Harakosan, 2009

4. C. J. A. Versteegh, "Design of the Zephyros Z72 wind turbine with emphasis on the direct drive PM generator", NORPIE 2004, NTNU Trondheim Norway 14 - 16 June, 2004. 